\title{
Eugene Giddens. How to Read a Shakespearean Play Text. Cambridge: Cambridge University Press, 2011. Pp ix, 187.
}

Mainstream critical interest in scholarly editing and textual studies has increased over the past two decades in Shakespeare and early modern studies but there are precious few introductory guides readily available to assist the uninitiated. Although the valiant efforts of Oak Knoll Press ensure that foundational bibliographical works by Fredson Bowers, Philip Gaskell, R.B. McKerrow, and others remain available as affordable paperback reprints, these earlier, lengthier studies can be intimidating for those modern students and scholars who lack any prior bibliographical training (a situation that is becoming increasingly commonplace). Routledge's acquisition of Garland's back catalogue of reference titles similarly ensures that D.C. Greetham's immensely useful Textual Scholarship: An Introduction (New York, 1994) remains available in paperback until the long awaited second edition is published. More recently, Mark Bland addressed the need for an updated handbook to analytical and descriptive bibliography with $A$ Guide to Early Printed Books and Manuscripts (Malden and Oxford, 2010) but its publication exclusively as a $£ 70.00 / € 84.00$ hardcover continues to limit the wider readership it deserves and to hinder its adoption in the classroom.

With How to Read a Shakespearean Play Text, Eugene Giddens fills a gap in the market for an affordable introduction to those aspects of bibliography and textual studies of most interest and practical use to the student and scholar of Shakespeare and early modern drama. As the volume costs only $\$ 28.95$ for a handsome paperback with some 20 illustrations, every student, scholar, and library can and should own a copy. Writing in his characteristically lively style, Giddens begins by guiding the reader through the cultural and mechanical processes by which early modern printed plays were produced, revised, censored, and adapted and finally made their way to the printing house. The second chapter provides a descriptive survey of material and typographical features of early printed play texts ranging from paratext to speech prefixes, running titles to colophons, and catchwords to signatures, offering a consideration of their functions for printers and publishers. The third chapter, 'Reading the Originals', addresses how the features outlined in the previous chapter shape an understanding of the plays themselves, and does so from the perspective of a modern editor analyzing the text. As a distillation of Giddens' extensive experience as an editor for the Revels, Cambridge Jonson, and Oxford Shirley series, this chapter alone justifies 
purchasing the book. Unless one begs, borrows, or steals the guidelines produced for large editorial projects such as those mentioned above - or perhaps takes David Bevington or Eric Rasmussen hostage — such a step-bystep editorial guide to examining early textual witnesses is, to my knowledge, otherwise unavailable. The final chapter turns to modern scholarly editions of early modern plays, considering how conventions of reproducing and editing - particularly in terms of spelling and punctuation, stage directions, collation, and other apparatus - shape the experience and understanding of the reader. Though print editions are its primary focus, the chapter includes a (somewhat sobering) discussion of electronic editions.

Introductions to a subject are by necessity selective and How to Read a Shakespearean Play Text is no exception. From the outset, Giddens makes it clear that his book 'is primarily concerned with the reading of printed play texts' (5); this emphasis explains the lack of attention paid to play texts in manuscript, which are discussed only in terms of their relationship to the printing house. While this is perhaps understandable, we live in an era not only of increased electronic access to photo-facsimiles of early printed play texts - whether through subscription services like Early English Books Online (ЕЕВO) or through openaccess projects like the Internet Shakespeare Editions, the Shakespeare Quartos Archive, or many of the digitized collections of research libraries and institutions - but also, to an extent, of similarly increased access to manuscripts. Many dramatic manuscripts from the period are available in photo-facsimile through British Literary Manuscripts Online, which, like EEBO, offers digitized microfilm images via institutional subscription. That said, the worthy task of expanding How to Read a Shakespearean Play Text to address manuscript play texts more fully would require more than an additional chapter to do it justice and might result in a book twice the size of the original. The only other glaring omission, given the volume's appeal as an introduction, is a glossary of terms, which might have been enormously beneficial to student and lay readers. Such a glossary certainly might have saved readers unfamiliar with some of the (admittedly common) terms, sigla, and symbols that Giddens uses without explanation (such as 'v' for 'verso' in signature references, superscripted in block quotations but otherwise in regular case throughout) from having to look outside the text for definitions.

How to Read a Shakespearean Play Text is a misleading and reductive title for this volume, and is clearly the product of a market-savvy attempt by Cambridge to increase sales. 'Shakespearean' is an infinitely more marketable keyword than 'early modern', and while Early Modern Printed Play Texts: 
A Bibliographical Primer, Editorial Guide, and Textual Introduction might be a more accurate (not to say verbose) title in hindsight, the reality is that 'bibliography' is simply not as sexy a term as 'reading. The book's extensive discussion of other dramatists, with half of its illustrations gleaned from outside the Shakespeare corpus, clearly indicates that Giddens' subject-matter is far more than just 'Shakespearean' in the limited sense that a reader might intimate from the title alone. In much the same way, Lukas Erne's Shakespeare's Modern Collaborators (London and New York, 2008) functions as a superb primer on editorial theory and practice in general as much as it offers a persuasively argued mission statement for the continued importance of editing Shakespeare in particular. Indeed, one could easily teach a graduate seminar on editing early modern drama, and not just Shakespeare, with Giddens and Erne as set texts. Neither book should be judged by its title.

In conclusion, How to Read a Shakespearean Play Text is a solid but gentle introduction to the bibliographical and textual principles, methods, and issues most relevant to the study of early modern drama in print. It is not a substitute for the lengthier bibliographical tomes of Bowers, Greg, Gaskell, McKerrow and the like, nor does it claim to offer an exhaustive treatment of its subject. Giddens writes in an engaging, straightforward style that will not alienate a student readership (as many of the earlier handbooks may do). At the same time, the content is in no way diluted or reduced to appeal to a lay audience. Indeed, scholars new to textual studies will find this book immensely useful as an introduction, while trained bibliographers may benefit from it as a primer or be stirred by the occasional pointers for future directions scattered throughout the text.

Brett D. Hirsch

\section{Max Harris. Sacred Folly: A New History of the Feast of Fools. Ithaca: Cornell University Press, 2011. Pp xi, 322.}

According to E.K. Chambers (summarizing a contemporary report), one of the last accounts of a clerical Feast of Fools in France involved Franciscan lay brothers who 'put on the vestments inside out, held the books upside down, and wore spectacles with rounds of orange peel instead of glasses. They blew 